DOI https://doi.org/10.30525/978-9934-26-109-1-12

\title{
A PRINCIPALLY NEW CONTROL SYSTEM FOR OPERATING MODES OF THE INTEGRATED POWER SYSTEM OF UKRAINE USING AUTOMATICALLY CONTROLLED ELECTRIC POWER COMPLEXES
}

\author{
Lenchevsky Ye. A. \\ Candidate of Technical Sciences, Senior Researcher, \\ Senior Scientific Researcher at the Department \\ of Forecasting the Development and Management \\ of the Electric Power Industry \\ Institute of General Energy of National Academy of Sciences of Ukraine
}

\section{Teslenko O. I.}

Candidate of Technical Sciences,

Senior Scientific Researcher at the Department

of Energy Efficiency and Optimization of Energy Consumption

Institute of General Energy of National Academy of Sciences of Ukraine

\section{Kyiv, Ukraine}

Studies conducted at the Institute of General Energy of the National Academy of Sciences of Ukraine have shown that there is a promising opportunity to implement a project aimed at eliminating the existing deficit of maneuverability. It is proposed to do this by showing the indicators of economic and environmental efficiency in the Integrated Power System of Ukraine (IPSU).

The possibility of creating a fundamentally new system of automatic frequency and power control using modern consumer- regulators was economically justified in [1, p. 20-28.]. the possibility of using automatically controlled loading of electric heat generator complexes (EHG) as operating means of the automated control dispatch system (ACDS) was considered in [2, p. 50-57; 3, p. 53-58].

It is assumed that the EHG complexes will include powerful electric boilers and technologically involved in existing CHPs and heat plants of the cities, which will have automatic control only from the existing ACDS of the IPSU.

For example, in Fig. 1 demonstrated the daily schedule of generation/ consumption of electric energy (DSEE) of the IPSU, for 14.02.2017, which 
conditionally shows the processes of compaction of this daily schedule automatically controlled load of EHG complexes.

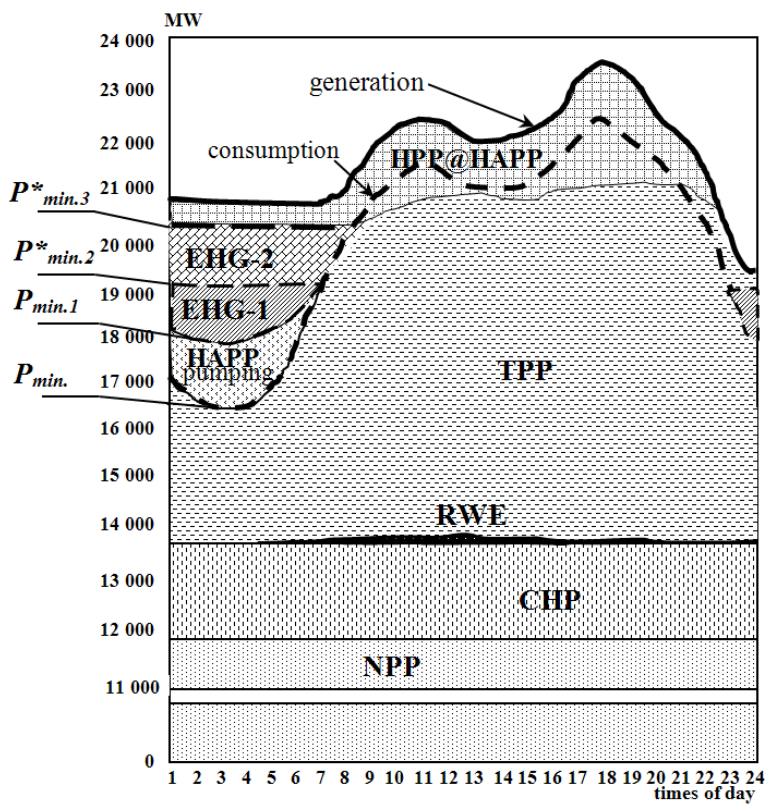

Fig. 1. Daily schedule of electricity generation / consumption of the IPSU, for 14.02.2017, where the load of EHG complexes is used

to raise the minimum level of the DSEE load to a new higher level

According to statistics in 2017, about 36 units of thermal power plants (TPP) were used daily to cover the DSEE load. At the same time, during the night failure of the DSEE load, the TPP dispatchers temporarily stopped from 7 to 10 units. There were 29 pulverized coal power units with a capacity of $(175$ - 300) MW and 2 double - units of TPP of power generating companies.

Today, the value of the minimum load level of the DSEE of the IPSU is set using the load capacities of the electric drives of the hydroelectric power plants (HPPs), at the mark P* ${ }_{\min 1}$ (Fig. 1). However, this level of minimum of the DSEE load $\left(\mathrm{P}^{*}{ }_{\min 1}\right)$ is not enough to ensure the process of regulating the regime throughout the night decline of the DSEE. Therefore, dispatchers of TPP are forced to temporarily disconnect part (about 10 units) of maneuverable power units of TPPs every day. 
In order to raise the minimum level of the DSEE load to a new higher level, we are proposed to use automatically controlled load of EHG complexes, integrated into the means of the ACDS of the IPSU. It is assumed that it is due to the control processes of the ACDS of automatically controlled loading of EHG complexes that it will be possible to raise the minimum level of ACDS $\left(\mathrm{P}^{*}{ }_{\min }\right)$ to a new higher level $\mathrm{P}^{*}{ }_{\min 2}$ (or $\mathrm{P}^{*}{ }_{\min 3}$ ) and keep it throughout the night decline of ACDS load (Fig. 1).

If the minimum level of DSEE load is raised to the mark $\mathrm{P}^{*}{ }_{\min 2}$ (Fig. 1 and Fig. 2), this will mean that the base part of the DSEE load will increase by $1000 \mathrm{MW}$, and its maneuverable part will decrease accordingly. This will eliminate the need for temporary shutdowns of 10 units of the TPPs at night and ensure their operation in the basic.

In the case of raising the minimum level of DSEE load to the mark $\mathrm{P}^{*}{ }_{\text {min } 3}$ the base part of the DSEE load will increase to $2000 \mathrm{MW}$. This will provide an opportunity to switch to the basic load mode of about 30 maneuverable units of the TPPs.

It should be taken into account that these 30 TPP power units contain a reserve of maneuverable generating capacity of $1000 \mathrm{MW}$. This reserve can be used for another purpose, i.e. to create a normalized primary reserve.

However, for the IPSU, it will be more appropriate to use a secondary capacity reserve designed to compensate for the most probable accidental loss of generation or consumption (ALGC). This reserve should be 1,500 MW (1000 MW for loading and $500 \mathrm{MW}$ for unloading).

The most promising direction in solving the issue of creating a new capacity reserve of the ALGC system may be the introduction of a permanent load mode of the IPSU up to 500 (or 1000) MW capacity of automatically controlled loading of EHG-1 complexes, as shown in Fig. 2 a.

At the same time, it is assumed that in the ALGC system in the mode of unloading of the IPSU the capacities of the EHG-2 complexes will be used, and in the mode of its loading the other $1000 \mathrm{MW}$ of capacities provided by the EHG-1 complexes will be used.

To perform emergency response processes in the IPSU it is proposed use EHG complexes into the ALGC system, which will include powerful electric boilers of the Swedish company Zeta [4]. The speed of power collection of the Zeta electric boilers from the minimum to the nominal value will be no more than 2 minutes.

In the process of regime regulation it will be possible (partially) to eliminate also the peak loads of ACDS, as it is conditionally shown in Fig. 2 b. 


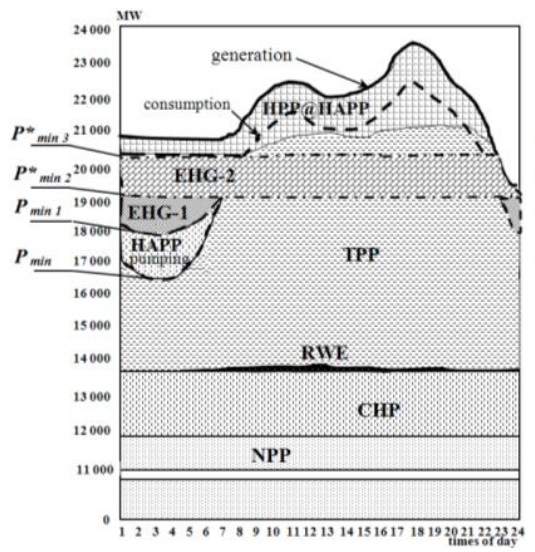

a)

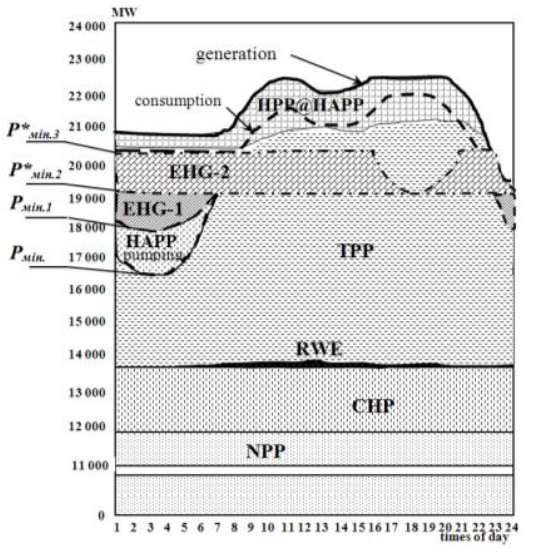

b)

Fig. 2. Daily schedule of electricity generation / consumption of the IPSU for 14.02.2017, which conditionally shows how automatically controlled load of EHG complexes (EHG-1 and EHG-2): a) provides a constant load in the ACDS throughout the day; b) helps to eliminate peak loads of ACDS

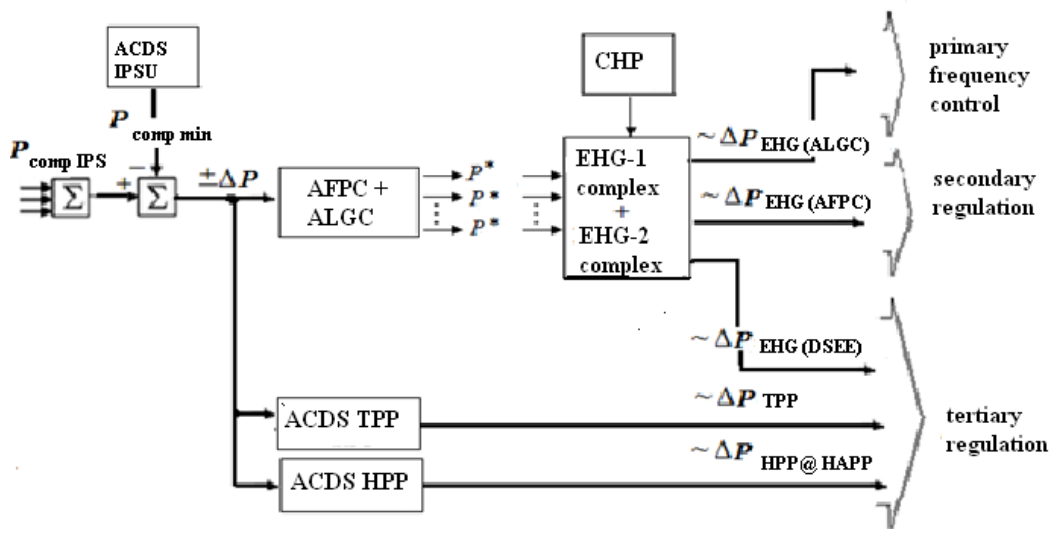

Fig. 3. The structural composition of the implementation of the processes of primary secondary and tertiary regulation using the ETG complexes in the AFPCS systems and the ALGC systems and the CHP ACDS in the IPSU 
Thus, due to the use of EHG complexes automatically controlled by the automatic control system of the power system will be quite possible perform primary (automatic frequency and power control - AFPC) and secondary control processes (accidental loss of generation or consumption - ALGC) systems, as shown in Fig. 3.

The structural composition of the new system of primary, secondary and tertiary regulation tasks in the IPSU with the use of automatically controlled load of the EHG complexes is shown in Fig. 3.

According to Fig. 3 teams of the ACDS of IPSU $( \pm \Delta \mathrm{P})$ will arrive in the control dispatch centers of CHP to perform automatically controlled loading of EHG complexes:

- commands of primary frequency control (due to the use of the ALGC system);

- processes of secondary regulation of the AFPC system;

- tertiary regulation processes (with DSEE compaction ).

Conclusions. The analysis identified a promising direction in addressing the topical issue for the IPSU on the possibility of providing in the latter full (according to standards) reserves of maneuvering capacity to perform primary secondary and tertiary regulation, through the use of automatically controlled loading of EHG complexes.

\section{References:}

1. Kulyk M.M. Techno-Economic Aspects of Using ConsumersControllers in Automatic Frequency and Power Control Systems. The Problems of General Energy. 2015. № 1(40). Pp. 20-28. DOI: https://doi.org/10.15407/pge2015.01.020 [on Ukrainian].

2. Lenchevsky Ye.A. Automation control of high-power electric boilers as an efficient way of decreasing the nonuniformity of diurnal curves of power loads of the Integrated Power System. The Problems of General Energy. 2016. № 4(47): Pp. 50-57. DOI: https://doi.org/10.15407/ pge2016.04.050 [on Ukrainian].

3. Lenchevsky Ye.A. Features of the use of electric heat generators in the processes of compaction of diurnal graphs of the electrical load of a power system. The Problems of General Energy. 2019. № 1(56). Pp. 53-58. DOI: https://doi.org/10.15407/pge2019.01.053 [on Ukrainian].

4. Electric boilers of the Swedish company Zeta. URL: http://zeta.se/ boilers/en/projects/sweden/ (access date: 10.05.2021). 